\title{
O teatro na alfabetização de adultos: Paulo Freire em tempos de pandemia
}

Carlos Henrique Chaves da Silva

Mestre pelo Programa Interdepartamental de Pós-Graduação Interdisciplinar em Artes, Urbanidades e Sustentabilidade da UFSJ. Jornalista, ator e professor voluntário de teatro de pessoas com Deficiência Intelectual e Múltipla.

E-mail: kaikechaves76@gmail.com

Filomena Maria Avelina Bomfim

Doutora em Comunicaşão e Cultura pela UFRJ. Professora do Programa Interdepartamental de Pós-Graduação Interdisciplinar em Artes, Urbanidades e Sustentabilidade da UFSJ.

E-mail: fmabomfim@ufsj.edu.br

Resumo: Este artigo busca confirmar que a utilização do método de alfabetização de adultos de Paulo Freire, aliado ao teatro como prática educomunicativa, configura uma ferramenta eficaz para a alfabetização de adultos, mesmo a distância. Apresenta-se uma metodologia para a alfabetização baseada na experiência de vida do estudante, por meio dos círculos de cultura, da expansão vocabular e do trabalho com as palavras geradoras. A pesquisa analisou adultos com idades entre 40 e 65 anos da Escola Municipal Maria Teresa, em São João del-Rei, que passaram por três níveis de alfabetização: alfabetização midiática; alfabetização por meio de narrativas e da construção de personagens fictícios; e a alfabetização construída a partir da relação com o outro e com o mundo.

Palavras-chave: alfabetização; educação; educomunicação; teatro; diálogo.
Abstract: This article seeks to confirm that the use of Paulo Freire's Adult Literacy Method, combined with theater as an educommunicative practice, configures an effective tool for adult literacy, even for distance learning. This article presents a methodology for literacy, based on the student's life experience, through cultural circles, vocabulary expansion and work with generative words. The study analyzed adults, aged between 40 and 65, from the Maria Teresa Municipal School, in the municipality of São João del-Rei, that went through three levels of literacy: media literacy; literacy through narratives and the construction of fictional characters; and literacy built from the relationship with other human beings and with the world.

Keywords: literacy; education; educommunication; theater; dialogue. 


\section{INTRODUÇÃO}

Em pleno 2021, ano em que é comemorado o centenário de Paulo Freire, este artigo revela a atualidade da obra do educador diante do panorama das redes sociais, das novas tecnologias e da pandemia da covid-19.

Atemporais, as influências de Freire são também um ato de resistência perante uma política que sucateia a educação e assombra o país com as sequentes denúncias sobre a rejeição, pelo governo federal, da compra de vacinas no início da pandemia do coronavírus e a falta de planejamento para o enfrentamento da covid-19, que ainda ocasiona mortes pelo país.

A metodologia de Freire, adaptada por meio da inserção do teatro enquanto prática educomunicativa, mostra que é possível alfabetizar adultos via WhatsApp, como comprova a aplicação da pesquisa $O$ teatro como prática educomunicativa na alfabetização de adultos. Trata-se de uma dissertação de mestrado, defendida no Programa Interdepartamental de Pós-Graduação em Artes, Urbanidades e Sustentabilidade (Pipaus) da Universidade Federal de São João del-Rei (UFSJ), que trabalhou com adultos com idades entre 40 e 65 anos do Programa de Educação de Jovens e Adultos (EJA), baseado na Escola Municipal Maria Teresa, em São João del-Rei, de março a novembro de 2020.

Com o objetivo de ampliar o debate e comprovar a atualidade do método de alfabetização de Paulo Freire, a pesquisa teve como ponto de partida o desinteresse dos estudantes do EJA. Neste sentido, o desafio desta pesquisa nasceu da problemática: como reverter ou, pelo menos, minimizar esta situação, formando cidadãos críticos e dispostos a aprender com base em suas experiências de vida?

\section{REFERENCIAL TEÓRICO}

O referencial teórico desta pesquisa é formado pelos conceitos de alfabetização, Educomunicação e teatro. Dessa forma, reconhece-se um saber previamente construído por aqueles que já refletiram sobre algumas abordagens teóricas que se aproximam dos conceitos que compõem a plataforma conceitual em foco, com atenção especial para os trabalhos desenvolvidos por Freire.

Quando o assunto é educação de qualidade baseada na experiência de vida do estudante, não há como não recorrer ao Patrono da Educação, o pernambucano Paulo Freire. Sustentáculo da pesquisa apresentada neste artigo, o educador e militante dedicou a vida à construção de uma educação libertadora, direcionada sobretudo às camadas populares. Ele lutou contra as relações opressoras do capitalismo para formar produtores de cultura. "Todo ato de pensar exige um sujeito que pensa, um objeto pensado, que mediatiza o primeiro sujeito do segundo, e a comunicação entre ambos, que se dá através dos signos

1. FREIRE, Paulo. Extensão ou comunicação? 8. ed. Rio de Janeiro: Paz e Terra, 1985, p. 44. linguísticos. O mundo humano é, desta forma, um mundo de comunicação"1.

Freire é lembrado como o intelectual que mostrou a profunda coerência entre teoria e prática da educação e do educador. Revolucionário que contrariou 
a concepção de educação como uma prática neutra, o pedagogo mostrou a importância e a necessidade de militância na Educação. Sua pedagogia considera o conhecimento como uma possibilidade de superar os modelos mecanicistas, de analisar a realidade social e de implantar novas propostas educacionais que promovam esperança e indiquem a necessidade de mudança.

Os elementos defendidos por Freire são organizados a partir de suas próprias considerações e da reinterpretação ou inovação de teorias existentes. Com práticas elaboradas na vivência com os excluídos, por meio do diálogo experienciado e da busca pela emancipação social, Freire constrói uma reflexão e elabora uma teoria pedagógica para as classes populares. Sua preocupação se centrava em um processo de aquisição de conhecimento que propiciasse aos indivíduos excluídos a aquisição da capacidade de compreender o funcionamento da sociedade em que se encontravam e a assunção de uma postura crítica a partir do reconhecimento de seus direitos e deveres e da conscientização sobre a prática cidadã. "Não é no silêncio que os homens se fazem, mas na palavra, no trabalho, na ação-reflexão. Mas, se dizer a palavra verdadeira, que é trabalho, que é práxis, é transformar o mundo, dizer a palavra não é privilégio de alguns homens, mas direito de todos os homens"2.

Paulo Freire almejava uma pedagogia libertadora e promotora do diálogo permanente. Para tanto, propôs uma pedagogia dialógica, ou seja, uma pedagogia que parte da problematização da realidade dos educandos, objetivando gerar mudanças significativas no mundo. Para Freire, a educação popular contesta, em sua essência, o sistema político e a ordem econômica vigentes e se faz popular justamente pelo potencial de organização da classe trabalhadora.

Sob esta ótica, vale ressaltar que o propósito fundamental da Educação é tornar o sujeito agente político, no sentido de que este atue como um participante ativo na transformação do mundo e da sua história, recuperando a humanidade que lhe foi roubada e negada. Neste sentido, é preciso fazer com que o educando se dê conta de seu próprio processo de conscientização, haja vista que ninguém é sujeito da educação de ninguém, a não ser de si mesmo.

Não há conscientização se, de sua prática, não resulta a ação consciente dos oprimidos, como classe explorada, na luta por sua libertação. Por outro lado, ninguém conscientiza ninguém. $\mathrm{O}$ educador e o povo se conscientizam através do movimento dialético entre a reflexão crítica sobre a ação anterior e a subsequente no processo de luta ${ }^{3}$.

A educação de jovens e adultos é reconhecida pela Organização das Nações Unidas para a Educação, a Ciência e a Cultura (Unesco) como um direito humano, estando implícita no direito à educação, reconhecido pela Declaração Universal dos Direitos Humanos, a começar pelo primeiro nível, que é o da alfabetização. A alfabetização é a base para a aprendizagem ao longo da vida. Nenhuma educação é possível sem as habilidades da leitura e da escrita.

A alfabetização é um direito em si mesma - precisamente porque, sem ela, as pessoas não têm oportunidades iguais na vida [...]. Aqueles que podem utilizar
2. FREIRE, Paulo. Pedagogia do oprimido. 17. ed. Rio de Janeiro: Paz e Terra, 1987, p. 50 .

3. FREIRE, Paulo. Ação cultural para a liberdade e outros escritos. 6. ed Rio de Janeiro: Paz e Terra, 1982, p. 109-110. 


\section{comunicação \& educação • Ano XXVI • número 2 • jul/dez 2021}

4. RICHMOND, Mark; ROBINSON, Clinton; SACHS -ISRAEL, Margarete (ed.). O desafio da alfabetização global: um perfil da alfabetização de jovens e adultos na metade da década das Nações Unidas para a alfabetização 2003-2012. Brasília, DF: Unesco, 2009 p. 19-28.

5. O círculo de cultura é um método criado por Paulo Freire que parte do pressuposto da construção do conhecimento por meio do diálogo - fator básico e necessário à prática pedagógica democrática. Mais informações podem ser obtidas em:https://eventos.ifpb.edu. br/index.php/v-enex/index/ pages/view/c\%C3\%ADrculos\%20de\%20cultura.

6. SOARES, Magda. Letramento e alfabetização: as muitas facetas. Revista Brasileira de Educação, São Paulo, n. 25, p. 5-16, 2004, p. 16.

7. MORAIS, Artur Gomes de; ALBUQUERQUE, Eliana Borges C. Alfabetização e letramento. Recife: Autêntica, 2007, p. 15

8. FERNANDES, Maria. Os segredos da alfabetização. 2. ed. São Paulo: Cortez, 2010, p. 19.

9. STEIN, Suzana A. Por uma educação libertadora. Petrópolis: Vozes, 1985, p. 58. a escrita e a leitura para defender e exercer seus direitos legais têm vantagem significativa em relação àqueles que não podem. Por intermédio da alfabetização, os indivíduos obtêm os meios de participação política na sociedade ${ }^{4}$.

Nesse sentido, o método de Paulo Freire é inovador e exemplar. Apropriando-se criticamente - não mecanicamente - do método, o adulto inicia a formação rápida do seu próprio sistema de sinais gráficos e começa a criar palavras por meio de combinações fonéticas. É desta forma que o educador descreve o processo de alfabetização, apresentando como resultado a alfabetização, em 45 dias, de cortadores de cana-de-açúcar em Angicos, no Rio Grande do Norte, onde foi implantado um dos primeiros "círculos de cultura".

Paulo Freire, assim como outros autores, debruçou-se sobre inúmeras pesquisas na intenção de compreender o processo de alfabetização. Quais os melhores métodos? Saber ler e escrever significa apenas decodificar códigos? Ao alfabetizar, é possível desconsiderar o letramento? Alfabetizar não seria propor bem mais do que ensinar a ler e a escrever? São muitos os questionamentos; ainda há muito para refletir, indagar e questionar. De qualquer modo, diferentes linhas, educadores e formas de pensar a alfabetização enriquecem o debate sobre o que já existe e o que está por vir no processo contínuo de educar e formar novos cidadãos. Ademais, quando se trata da alfabetização de adultos, há de se considerar a bagagem de vida que os estudantes trazem para a sala de aula quando decidem retornar à escola.

Segundo Soares ${ }^{6}$, "a alfabetização é entendida como um processo de aquisição e apropriação do sistema da escrita, alfabético e ortográfico”. Morais e Albuquerque complementam:

Alfabetização: processo de aquisição da "tecnologia da escrita", isto é, do conjunto de técnicas - procedimentos/ habilidades - necessárias para a prática de leitura e da escrita: as habilidades de codificação de fonemas em grafemas e de decodificação de grafemas em fonemas, isto é, o domínio do sistema de escrita (alfabético ortográfico) $)^{7}$.

Alfabetizar é oferecer ao aluno a oportunidade de se expressar, propondo ferramentas para que ele possa construir o seu próprio conhecimento.

Hoje, os grandes objetivos da Educação são: ensinar a aprender, ensinar a fazer, ensinar a ser, ensinar a conviver em paz, desenvolver a inteligência e ensinar a transformar informações em conhecimento. Para atingir esses objetivos, o trabalho de alfabetização precisa desenvolver o letramento. O letramento é entendido como produto da participação em práticas sociais que usam a escrita como sistema simbólico e tecnologia ${ }^{8}$.

Quando o indivíduo questiona sua relação com os outros e com o mundo, aprendendo, de fato, ao descobrir um problema, a alfabetização é libertadora. "O homem olha a situação; começa a descobrir, com seu grupo, as situações que o oprimem, e, através da discussão de problemas que realmente o interessam, cuja solução lhe é urgente, vai descobrindo a palavra, sobre a qual pensa e fala" . 
Nesta pesquisa, o conceito de alfabetização tem o teatro como ferramenta educomunicativa e descarta o método de alfabetização mecânico, que não engloba o letramento e as experiências de vida de um adulto nem reflete suas necessidades ao propor, durante o processo, cartilhas que infantilizam o ensino e geram a possibilidade de o estudante não se identificar com o que aprende. "A uva é do vovô" ou "A bola é da Bia" são frases que não se encaixam no contexto de vida dos estudantes da EJA, e, se não há identificação, não há aprendizado.

As cartilhas, por boas que sejam, do ponto de vista metodológico ou sociológico, não podem escapar, porém, a uma espécie de "pecado original", enquanto são o instrumento através do qual se vão "depositando" as palavras do educador, como também seus textos, nos alfabetizandos. E por limitar-lhes o poder de expressão, de criatividade, são instrumentos domesticadores ${ }^{10}$.

Os autores citados tendem a não aceitar de forma irrestrita o sistema de alfabetização mecânico, que impõe um saber já pronto e propõe ao adulto cartilhas direcionadas às crianças. Tais atividades trazem lições que não condizem com a realidade do estudante da EJA.

Em geral, porém, tanto as palavras quanto os textos das cartilhas nada têm que ver com a experiência existencial dos alfabetizandos. E quando o têm, se esgota esta relação ao ser expressada de maneira paternalista, do que resulta serem tratados os adultos de uma forma que não ousamos sequer chamar de infantil. Este modo de tratar os adultos analfabetos implícita uma deformada maneira de vê-los - como se eles fossem totalmente diferentes dos demais ${ }^{11}$.

Contudo, todos concordam que a alfabetização se faz a partir da tecnologia da escrita, que é o conjunto de técnicas, habilidades e procedimentos necessários para sua prática. Eles são unânimes ao afirmarem que a alfabetização se concretiza com base nas experiências de vida do adulto e que o letramento ocorre antes mesmo de o sujeito ingressar na escola, caso ele tenha consciência crítica do contexto em que vive. Se o indivíduo pensa e age em sua comunidade, na igreja ou na associação de moradores, é letrado. Os autores também concordam que a escola é apenas uma das unidades do letramento, que tem como missão não apenas ensinar a ler e a escrever, mas também propiciar o entendimento sobre o que se lê e o que se escreve.

Por isso, tendo como referências autores e educadores que defendem a alfabetização libertadora, a investigação científica apostou em um conceito de alfabetização que ofereceu ferramentas e instigou o estudante a buscar o aprendizado por meio da apropriação de suas próprias experiências, construindo, assim, uma trajetória educacional que lhe permita fazer uso da palavra para expor o que pensa, exprimir seus desejos e dialogar com o outro e com o mundo, além de saber ser crítico e formular os próprios pensamentos e opiniões. Tal conceito de alfabetização permitiu, portanto, que o estudante, enquanto cidadão, soubesse agir de forma engajada diante das situações.

Foi preciso buscar formas para que a alfabetização fosse um processo de construção crítica prazeroso, eficiente e com total participação do estudante.

10. FREIRE, Paulo. Ação. Op. cit., p. 11

11. Ibidem, p. 12. 
Tem-se, dentre tais formas, a educomunicação, que trouxe um conjunto de ações e a iniciativa de melhorar a comunicação no ambiente escolar por meio de práticas dialógicas. Trata-se de uma alternativa para elevar a qualidade do ensino, baseando-se na experiência de vida e no cotidiano de quem está sendo alfabetizado. Tem-se como educomunicativo, por exemplo, o teatro do oprimido, de Augusto Boal, que contribui para o entendimento de que sua obra tinha a mesma proposta que a de Freire: reduzir a opressão e possibilitar a cidadania.

No teatro é possível observar como o povo foi sendo oprimido, segundo afirma Boal (1991), em seu livro O teatro do oprimido: e outras poéticas políticas. O teatro era do povo, uma festa feita nas ruas, até que a classe dominante tratou de separar quem iria assistir e quem faria teatro. Depois, veio a segunda ruptura e a imposição entre os atores, quando novamente os aristocratas decidem quem serão os protagonistas e quem integrará o coro. Para Boal, era preciso rever esta configuração para que o povo, oprimido, voltasse a ser agente e protagonista do fazer teatral, com o único objetivo, segundo o teatrólogo, de "transformar o povo, "espectador", ser passivo no fenômeno teatral em sujeito, em ator, em transformador da ação dramática ${ }^{12}$.

Por isso, o teatro, enquanto prática educomunicativa cuja força só pode ser entendida pelo conhecimento de sua história, faz-se presente e necessário na construção de uma nova metodologia de ensino.

Teatro, do grego theatrón, significa "lugar para ver, contemplar". É tanto o ramo das artes relacionado à atuação, em que são representadas histórias para uma plateia, quanto um gênero literário, em que as obras são escritas para serem encenadas. Além disso, teatro é também a definição do lugar, da estrutura física onde as peças são encenadas.

As primeiras manifestações que originaram o teatro vêm da união de antigos rituais sagrados para pedir ou agradecer por uma boa colheita, chuva ou um bom dia de caça e com música e dança, mas com a diferença de que tais rituais não eram feitos para que alguém assistisse, isto é, ainda não havia o público. Foi somente no século V a.C., na Grécia Antiga, que o teatro com as referências que chegariam ao ocidente, como os modelos tradicionais de tragédia e comédia, teve origem.

O tempo passou e o teatro evoluiu. Foram construídos locais específicos para as encenações, com acomodações confortáveis, investiu-se em melhores condições de som e iluminação e as peças ganharam cenários e figurinos. O teatro viveu diferentes fases, passando por várias transformações: do clássico ao contemporâneo, dos musicais ao teatro de bonecos. O público, que em uma época foi protagonista e em outra foi limitado a espectador, também foi convidado a voltar a participar, o que muitas vezes fez que desaparecesse o limite entre palco e plateia. Formou-se, assim, um teatro que resiste com sua arte de fazer de conta, que se concretiza na relação entre ator e plateia e que sempre esteve presente nas ruas, fora dos teatros, em praça pública, nos parques, nas estações de metrô e até na escola. 
A proposta da pesquisa foi, assim, engajar os alunos com as referências múltiplas que constituem as diferentes linguagens, experiências e códigos culturais. Isto significou educar os alunos não apenas para que eles lessem tais códigos criticamente, mas também para que aprendessem os limites destes, incluindo aqueles que eles usam para construir suas próprias narrativas e histórias. Nesta perspectiva, os alunos puderam construir o conhecimento, romper barreiras de aprendizagem e cruzar os limites construídos em volta das coordenadas da diferença e do poder.

Esse conceito se aplica fielmente a esta pesquisa quando se observa e se respeita a necessidade do alfabetizando de ter autonomia para construir o próprio conhecimento com base em suas experiências de vida. Assim, em vez de apenas ouvir e assimilar o conteúdo, o que se propõe é que, por meio do teatro, o estudante tenha voz ativa, saiba questionar e dialogar e esteja apto a se comunicar e a se inserir, de fato, no ambiente escolar. Ademais, que ele tenha condições de exercer seus direitos e de cumprir seus deveres enquanto cidadão. Para Koudela e Santana (2005), na pedagogia do teatro:

Educadores e alunos empregam convenções que desafiam, resistem e desmantelam sistemas de privilégio criados pelos discursos dominantes e práticas discursivas da moderna cultura do ocidente. Dessa forma, a prática da ação dramática cria espaços e possibilidades para dar forma à consciência pós-moderna e pós-colonial, sensíveis a pluralidade, diversidade, inclusão e justiça social ${ }^{13}$.

Os autores reúnem semelhanças com Giroux ${ }^{14}$ uma vez que acreditam que o teatro, aliado à Educação, pode ser transformador. Não somente, eles são uníssonos aos afirmarem que a comunicação é mais importante do que o método proposto e que o teatro tem o papel de levar o ser humano a perceber a complexidade das artes e da vida; feito na escola, propõe a ação e a reação contra a dominação. Os autores também concordam que a linguagem teatral proporciona a formação do ser crítico, construtor do próprio conhecimento, capaz de romper barreiras e de ter consciência plural e diversa, adequada ao contexto em que vive.

\section{OBJETO DE PESQUISA}

O objeto de pesquisa deste estudo foram as práticas educomunicativas, construídas com base no jogo teatral, utilizadas para despertar o interesse dos adultos da EJA matriculados na Escola Municipal Maria Teresa, em São João Del Rei (MG).

A Escola Municipal Maria Teresa foi inaugurada no governo de Fernando de Melo Viana em 2 de agosto de 1925. Em 1943, foi transferida para a Praça dos Expedicionários, onde funciona até hoje. Desde a sua fundação, funcionou como grupo escolar. Em 1978 passou a ser a Escola Estadual Maria Teresa e só em 2 de fevereiro de 1998 foi municipalizada.

13. KOUDELA, Ingrid Dormien; SANTANA, Arão Paranaguá de. Abordagens metodológicas do teatro na educação. Ciências Humanas em Revista, São Luís, v. 3 , n. 2, p. 145-154, 2005, p. 153.

14. GUILHERME, Manuela. Qual o papel da pedago gia crítica nos estudos de língua e de cultura? Entrevista com Henry A. Giroux. Revista Crítica de Ciências Sociais, [s. I.], n. 73, p. 131$143,2005$. 


\section{comunicação \& educação • Ano XXVI • número 2 • jul/dez 2021}

Em 2020, a escola atendeu 663 alunos e possuía 64 docentes e 38 funcionários em cargos administrativos, técnicos e de limpeza. Ela funciona em três períodos: manhã, atendendo o $1^{\circ}$ ano, $3^{\circ}$ ano, $4^{\circ}$ ano e $5^{\circ}$ ano; tarde, em que atende do $1^{\circ}$ ao $3^{\circ}$ ano; noite, período voltado para a $1^{\text {a }}$ à $5^{\text {a }}$ etapa, isto é, multisseriado equivalente ao $1^{\circ}$ e ao $5^{\circ}$ ano do ensino fundamental, da EJA. A partir de 2003, a escola passou a sediar a sua própria modalidade de EJA, sempre contemplando todo o ensino fundamental.

Em 2016, as turmas de EJA que funcionavam em outras duas escolas da cidade foram nucleadas na Escola Municipal Maria Teresa. Desde então, ela é a única escola que oferece EJA de ensino fundamental no município. São nove séries, divididas em nove turmas. A turma de alfabetização, foco desta pesquisa, é uma turma multisseriada, do $1^{\circ}$ ao $5^{\circ}$ ano do ensino fundamental.

De acordo com os dados de 2020, fornecidos pela secretaria da escola, 12 estudantes se matricularam na turma de alfabetização do programa. Destes, cinco participaram da pesquisa - três mulheres e dois homens, com idades entre 45 e 60 anos, cujas profissões variam entre donas de casa, comerciantes e trabalhadores informais. Trata-se de pessoas que nunca frequentaram a escola ou que desistiram no meio do percurso tanto pela falta de oportunidade quanto pela falta de incentivo dos pais, o que era habitual há algumas décadas.

\section{METODOLOGIA DE PESOUISA}

Elegeu-se como metodologia deste estudo a pesquisa-ação, devido à sua abordagem qualitativa, sob a escala de observação microssocial ${ }^{15}$. Trata-se de um tipo de pesquisa social e indutiva que foi concebida e realizada em estreita associação com uma ação, na tentativa de solucionar um problema coletivo em que pesquisadores e participantes estão envolvidos e participam juntos.

A opção pela pesquisa-ação se justifica porque, não só se buscou investigar um fenômeno, mas também transformá-lo com o intuito de solucionar um problema social. Nesse sentido, antes de planejar a ação - inserir o teatro na alfabetização de adultos -, pesquisar o fenômeno foi essencial.

Seguindo todas as etapas da pesquisa-ação, foram feitos o diagnóstico, o seminário de apresentação e avaliações e reavaliações constantes, sempre com a participação do pesquisador e com o envolvimento de todos os participantes.

Depois de um café mineiro, que reuniu os estudantes para apresentação da pesquisa no auditório da escola, em março de 2020, na semana seguinte,

15. THIOLLENT, Michel. Metodologia da pesquisa-ação. 12. ed. São Paulo: Cortez, 2003. o pesquisador e a turma de alfabetização se viram diante de algo inédito e foram surpreendidos com o surgimento da covid-19, uma doença respiratória até então desconhecida, que ainda em 2021 é uma preocupação. 


\section{APLICAÇÃO DA METODOLOGIA DE PESQUISA}

Foi criado, então, um grupo no WhatsApp, formado pelos estudantes do programa, a professora Carme Zim e a coordenadora Marta Dela-Sávia. O pesquisador foi convidado a ingressar na sala virtual e dar continuidade à pesquisa.

Antes de dar início às atividades, foi estabelecido o compromisso de que alunos, professores e pesquisadores se reunissem uma vez por semana, durante uma hora, no WhatsApp. Previamente, os estudantes sempre eram lembrados do horário da aula e sobre a necessidade de deixarem o celular carregado, para poderem participar das atividades

Entre os cinco alunos que aceitaram participar do estudo, poucos sabiam utilizar as funções do WhatsApp. Como a maioria não escrevia nem lia, as conversas eram registradas em áudio. Era preciso que aprendessem um pouco mais, por isso foi essencial postar gravações em vídeo no grupo, para que o real propósito da pesquisa - ensinar a ler e a escrever por meio do teatro - não fosse alterado.

Ficou evidente que, antes da aplicação da pesquisa, seria preciso ensinar como gravar vídeos e utilizar as demais funções do aplicativo de conversas. Deu-se início, assim, à primeira etapa: a alfabetização midiática. O pesquisador gravou um vídeo didático, mostrando na tela do celular o passo a passo do que deveria ser feito. Bastou esta explicação para que os primeiros vídeos dos estudantes fossem recebidos. Neles, eles se apresentaram e contaram por que pararam e por que voltaram a estudar.

Passada esta fase, seguiu-se para a segunda etapa: a alfabetização por meio de narrativas e da construção de personagens. Com base nas histórias enviadas, o pesquisador trabalhou a construção da história com começo, meio e fim. Em vídeo, o pesquisador gravou duas histórias: uma como pesquisador e outra como personagem. Utilizando a sua formação de ator, caracterizou-se de trabalhador rural para exemplificar a possibilidade de personagens que os estudantes poderiam criar. Também foi destacado que no teatro o espetáculo é feito para o público, e que, diante da nova maneira de comunicação, o espectador seria a câmera do celular, ou seja, era para ela que os alunos deveriam falar. Outros pontos importantes foram a construção dos personagens, o modo de se portar, o timbre da voz e a caracterização.

Na sequência, foi pedido que cada estudante, caracterizado do personagem que escolheu interpretar, relatasse como tem sido a experiência de ficar isolado em casa, durante a pandemia.

Demonstrando autonomia, independência e muita criatividade, os alunos revelaram em vídeo grandes potencialidades ao se comunicarem. Desinibidos, os personagens fictícios trouxeram sentimentos reais ao contarem como estava sendo difícil ficar longe da escola, das atividades rotineiras e dos familiares.

A terceira etapa de alfabetização, também inspirada pelos círculos de cultura e pelo método de alfabetização de Paulo Freire, trabalhou a alfabetização por meio de um levantamento vocabular com base na experiência de vida dos estudantes e das palavras geradoras. 


\section{comunicação \& educação • Ano XXVI • número 2 • jul/dez 2021}

16. FREIRE, Paulo. Ação..

Op. cit., p. 16.

17. ARSEL, Zeynep. Fazendo perguntas com um foco reflexivo: um guia para o planejamento e condução de entrevistas. Revista Interdisciplinar de Marketing, Maringá, v. 8, n. 2, p. 84 98,2018

18. ROOK, Dennis W. Let's pretend: projective methods reconsidered. In: BELK, Russell W. (ed.). Handbook of qualitative research methods in marketing. Cheltenham Glos: Edward Elgar, 2006. p. 143-155.

19. GOLDENBERG, Mirian. $A$ arte de pesquisar. Rio de Janeiro: Record, 1997.

20. SOARES, Ismar de Oliveira. Educomunicação: o conceito, o profissional, a aplicação - contribuições para a reforma do ensino médio. São Paulo: Paulinas, 2011.
As palavras geradoras - palavras do povo - são postas em situações problemas (codificações), como desafios que exigem resposta dos alfabetizandos. Problematizar a palavra que veio do povo significa problematizar a temática a ela referida, o que envolve necessariamente a análise da realidade, que se vai desvelando com a superação do conhecimento puramente sensível dos fatos pela razão de ser dos mesmos ${ }^{16}$.

A cada semana, a história de um estudante era exibida em vídeo no grupo de WhatsApp. O pesquisador então selecionava uma palavra daquela história, que era separada em sílabas, para que os estudantes sugerissem outras palavras, a partir daquelas sílabas. Assim foram trabalhadas a leitura e a escrita via WhatsApp, ao longo de 2020.

Encerradas as atividades de aplicação da pesquisa, a pedido dos estudantes, o pesquisador permaneceu no grupo e deu sequência ao trabalho, atendendo às demandas.

Neste período, que se seguiu até novembro de 2020, foram trabalhados: o uso do érre (R) e do ésse (S); o teatro fórum de Augusto Boal, que propõe uma ação em busca de uma solução e trabalha a autonomia e a criatividade; a separação de sílabas; a escrita dos números; ditados, leitura e escrita, a partir de cartazes, placas, números de residências e anúncios que eram fotografados pelo pesquisador nas ruas de São João del-Rei e apresentados no grupo de WhatsApp.

\section{ANÁLISE DE CONTEÚDO}

$\mathrm{O}$ instrumento de pesquisa escolhido foi o roteiro semiestruturado de perguntas abertas para entrevistas em profundidade sugerido por $\mathrm{Arsel}^{17}$, aliado às técnicas projetivas de Rook $^{18}$ e à observação participante de Goldenberg ${ }^{19}$. Cada dia de aplicação da pesquisa foi registrado em um diário de bordo.

A técnica de análise de dados foi realizada de acordo com as variantes analíticas, criadas a partir do referencial teórico. Cada vivência foi analisada a partir dos conceitos estabelecidos no referencial. Foi possível identificar a dialogicidade presente na literatura de Freire, quando este propõe soluções para problemas identificados na realidade do estudante. Criou-se um ambiente, ainda que virtual, com ferramentas favoráveis à aprendizagem e propício ao diálogo, como prevê o processo educomunicativo de Ismar de Oliveira Soares ${ }^{20}$. Neste ambiente, os adultos podiam expressar suas dúvidas, alegrias e angústias, bem como comemorar cada conquista em relação à leitura, à escrita e ao entendimento de cada palavra, por meio do teatro.

\section{RESULTADOS DA PESQUISA}

Ao todo foram 28 encontros, e a análise de conteúdo foi essencial para a avaliação de todo o processo de pesquisa. Observando cada dia, todos registrados 
em um diário pelo pesquisador, foi possível verificar, com base nos conceitos, o quanto os estudantes evoluíram ao longo de todo o processo. O primeiro contato tímido, o desconhecimento sobre o uso da tecnologia e a vergonha de se expressar deram lugar a novas posturas. Com o passar do tempo e o avanço das atividades propostas, cada estudante buscou e conquistou protagonismo.

Foi no WhatsApp que aquele grupo reservado foi se revelando, dia após dia. A convivência trouxe a liberdade de um "bom-dia!" logo cedo, a preocupação com a ausência de algum colega na aula e até o compartilhamento de fotos de momentos casuais com as suas famílias. Estabeleceu-se um elo difícil de ser desfeito e foi inevitável a aproximação de todos pelo contato semanal.

No que se refere à utilização dos conceitos definidos no referencial teórico como variantes analíticas, observa-se que os mais evidentes foram: educomunicação, alfabetização e jogo teatral.

É nítido que, em um processo para ensinar o estudante a ler e a escrever, o conceito de alfabetização se estabelece fortemente, ainda mais quando tal conceito prevê uma educação libertadora, inspirada na experiência de vida do estudante, com espaço e abertura para o diálogo. Foi isto que aconteceu ao longo da pesquisa; a alfabetização inovadora, realizada por meio do teatro e totalmente on-line, foi essencial para possibilitar que os adultos voltassem a acreditar que eram capazes de aprender a ler e a escrever.

Inspirado em Paulo Freire, o método de retirar palavras das histórias de vida dos estudantes foi um estímulo. Ao se verem na tela do celular, contando as suas histórias, os estudantes se sentiram valorizados. Ademais, as palavras escolhidas para serem trabalhadas em aula tinham total relação com o universo deles, o que facilitou a assimilação. O conceito de alfabetização se fez presente em cada momento de aplicação da pesquisa - via WhatsApp -, como quando cada estudante exerceu o direito de falar e de arriscar a escrever uma palavra sem o medo de errar, juntou sílabas, formou palavras e frases, leu um texto e pôde compreender o que escreveu.

Os participantes da pesquisa se assumiram como seres sociais pensantes, protagonistas capazes de compreender a realidade em que vivem por meio da leitura, da escrita e do entendimento sobre o que leem e o que escrevem. Por meio da aplicação de um ditado individual e da sua leitura, foi possível comprovar a aprendizagem, revelando que, entre os cinco estudantes, a maioria concluiu a sua participação na pesquisa, atingindo o objetivo de aprender a ler e a escrever.

Impossibilitados de sair de casa por conta da pandemia, os estudantes se adequaram ao novo modelo de ensino remoto e se dispuseram a aprender a utilizar todas as ferramentas tecnológicas necessárias para a construção do conhecimento. Todo esse processo dialógico e tecnológico, que preparou um espaço amplo para o debate, só pôde ser viabilizado por meio da Educomunicação. Planejamento, acordos coletivos sobre horários de chegada e questões cujas soluções dependiam das decisões em grupo, o respeito à opinião do colega, o aprendizado da tecnologia e a relação que se estabeleceu entre pesquisador e 
estudantes formaram uma espécie de código de conduta, mas sem a necessidade de ditar regras, compondo um conjunto de ações educomunicativas.

Sem o entendimento do papel da Educomunicação na pesquisa teria sido impossível prosseguir. Foi a partir da possibilidade de estabelecer uma comunicação de igual para igual que a pesquisa de fato aconteceu, e bastou que os estudantes enxergassem no pesquisador um aliado para que a confiança fosse estabelecida. Foi por meio do processo educomunicativo que os estudantes puderam repensar a aprendizagem mecanicista, proposta pelas cartilhas, e se abrir para um modelo de alfabetização inovador, baseado nas suas experiências de vida e no seu cotidiano.

A pesquisa ressignificou a escola enquanto espaço complexo de comunicação e seu papel de considerar o estudante, seu entorno cultural e as pessoas com quem vive como bases de uma educação realista, prática e calcada na vivência do dia a dia. Dessa forma, a pesquisa devolveu o ânimo e a autoestima dos educadores, que estavam acostumados com a rotina e, por isso, muitas vezes, eram desmotivados a fazer o diferente.

Por último, mas não menos importante, o jogo teatral foi fundamental para a pesquisa, principalmente quando esta, em razão da pandemia, passou do meio presencial para a forma remota. Sem os exercícios de desinibição e exemplos práticos de como relaxar e de como se expressar, principalmente os propostos por Augusto Boal, os estudantes não teriam gravado os vídeos de apresentação, com a criação de personagens, nem teriam contado suas histórias de vida; talvez nem teriam aceitado participar. É inegável que houve uma resistência inicial, natural por conta da timidez, mas logo foi vencida pelo jogo teatral, que possibilitou o protagonismo.

Com o decorrer da pesquisa, durante as atividades gravadas em vídeo, os estudantes adquiriram uma nova postura ao se assumirem como cidadãos dotados de uma identidade individual e coletiva, críticos e capazes de avaliar e decidir juntos os caminhos que mais se adequavam às suas realidades durante o processo de aprendizagem. A gravação de vídeos foi um passo importante para estabelecer a comunicação, em tempos em que a distância física é uma necessidade.

Os estudantes identificaram problemas, propuseram soluções e se fortaleceram como indivíduos, sendo capazes de expressar suas alegrias, angústias e necessidades. Tais ações são exemplos de protagonismo na escola que, naturalmente, transpõe-se para a vida.

A análise evidenciou ainda uma preocupação dos estudantes. Em razão da idade avançada e da falta de oportunidades para estudar, eles querem aprender para que possam se estabelecer na sociedade com respeito e dignidade, seja conquistando um bom emprego, prosseguindo com os estudos ou sendo capazes de ler e assinar o próprio nome. Tal inquietação foi explorada em todas as atividades, com destaque para uma em que os estudantes passaram por uma entrevista fictícia de emprego para que soubessem como reagir diante desta futura realidade. Todos se saíram muito bem ao descrever as próprias 
características, sugerir uma média salarial e explicar o porquê de quererem trabalhar naquela empresa.

A Educomunicação, a alfabetização e o jogo teatral foram elencados para a análise das ações por terem em comum características que possibilitam a valorização do estudante enquanto cidadão, do espaço inovador e participativo e da comunicação dialógica. Além disso, as ações permeadas pela transdisciplinaridade possibilitaram o envolvimento e a integração de diferentes áreas do conhecimento, em uma troca significativa que contribuiu para o diálogo constante.

Estas categorias, destacadas pela marcante evidência que têm na pesquisa, demonstram o potencial deste trabalho na medida em que comprova que o conjunto de ações para promover a alfabetização libertadora foi eficaz ao possibilitar o diálogo, o ensino do uso das ferramentas tecnológicas, a construção de narrativas e a alfabetização com base na experiência de vida dos alunos.

A ênfase nos três conceitos é justificada pela forma como cada um contribuiu efetivamente para a construção de um processo de alfabetização único e inovador, já que, segundo a coordenadora Marta Dela-Sávia, foi a primeira vez que um trabalho é realizado desta maneira na EJA. A base desses três pilares permitiu que toda a aprendizagem se concretizasse, mesmo diante de uma situação caótica da pandemia do novo coronavírus. Foi por meio de tais conceitos que foram viabilizados e estabelecidos os encontros semanais, que se firmaram ao longo dos meses da pesquisa sem qualquer cobrança, contando apenas com a disponibilidade de todos de estarem presentes pela própria vontade e de executarem as atividades para, juntos, construir conhecimento.

Outro ponto importante que merece destaque foi o envolvimento das famílias dos estudantes. Em depoimento gravado em vídeo, a esposa de um deles ressaltou que também aprendeu a ler e a escrever e que se sentia orgulhosa cada vez que ela e o marido iam até a região central da cidade e ele lia todas as placas que via pela frente.

Vale ressaltar também o quanto a pesquisa se expandiu para além do grupo de WhatsApp. A cada resultado ou nova proposta, a professora da turma, Carme Zim, e a coordenadora da EJA, Marta Dela-Sávia, levavam a ideia a outros educadores da rede pública que, motivados, quiseram conhecer a aplicação da pesquisa desenvolvida na Escola Municipal Maria Teresa. Desde o primeiro e único momento presencial - o café mineiro para a apresentação da pesquisa - até o último dia da aplicação, o estudo foi bem aceito pelos estudantes, pela professora e por toda a comunidade escolar, estendendo-se até a Secretaria Municipal de Educação, devido a sua estrutura, planejamento, inovação e, principalmente, aos resultados obtidos ao longo do processo.

Aqueles estudantes do primeiro dia de aula já não se consideram mais os mesmos. Modificados pelo conhecimento e entusiasmados diante das inúmeras possibilidades, fazem planos: ser caixa de supermercado, abrir o próprio negócio, entrar para a faculdade etc. Adultos, antes sem perspectiva, voltaram a sonhar e retomaram a esperança de que não há idade para começar ou recomeçar algo. 
É impossível relatar essa trajetória sem mencionar a transformação promovida pela pesquisa. A cada dia de aula, depois de uma rotina puxada de trabalho, as senhoras e os senhores estudantes deram um exemplo de determinação ao focarem nos estudos. Aprenderam, mas também ensinaram quando o assunto é a perseverança e o desejo de realizar os próprios objetivos. Enquanto pesquisador, em nenhum momento, a pesquisa foi um fardo. Pelo contrário, durante os últimos meses, cada questionamento ou dúvida foi um motivo a mais para pesquisar, melhorar e evoluir. Foi prazeroso acordar e ir dormir pensando em formas de transmitir o conteúdo de maneira criativa, clara e objetiva. Isso tudo sem contar a relação de amizade que se estabeleceu entre mim e os participantes e que perdura, mesmo com o fim dos trabalhos.

Ficou, assim, a semente de uma iniciativa que deu certo, já que a professora que nos acompanhou na pesquisa se aposentou e a nova educadora segue com o trabalho no grupo de WhatsApp, inspirada por tudo que fizemos para concretizar a alfabetização de adultos por meio do teatro enquanto prática educomunicativa.

\section{CONSIDERAÇÕES FINAIS}

A pesquisa foi, sobretudo, uma longa jornada que teve como destino o conhecimento. Como meio de comunicação, o celular levou os estudantes a um processo de aprendizagem instigante, construído por meio das experiências de vida destes e o ensino calcado na realidade. Por meio de um passeio virtual pelo supermercado, pela padaria ou farmácia ou pela narração de suas próprias histórias, caracterizados como personagens, os alunos da turma da EJA tiveram a oportunidade de explorar diferentes caminhos lúdicos e reais durante o processo de alfabetização.

Percebeu-se que o teatro não só promoveu um processo prazeroso e instigante, mas também constituiu um dispositivo capaz de propiciar uma trajetória rumo à alfabetização mais consciente. O teatro, como prática educomunicativa, promoveu transformações. Por meio dele, os estudantes experimentaram a liberdade de escolher personagens relacionados com as suas próprias histórias de vida e que expressavam as alegrias, os sonhos, as tristezas e as angústias que tinham enquanto adultos em busca da alfabetização.

No que toca à utilização do WhatsApp, pode-se dizer que o aplicativo foi uma ferramenta determinante para a pesquisa. Como os estudantes tiveram que aprender a utilizar o aparelho para gravar áudios, vídeos e enviar mensagens, a autoconfiança que sentiram ao dominar a tecnologia os levou a acreditar que também seriam capazes de aprender a ler e a escrever. $\mathrm{O}$ celular se transformou, assim, em algo maior que um equipamento para falar ou mandar mensagens para outras pessoas; passou a ser o meio em que os estudantes protagonicamente promoveram o seu processo de alfabetização, sob a orientação de um educomunicador-pesquisador. 
Dessa forma, a sala de aula presencial deu lugar à sala de aula virtual mantida devido ao interesse dos estudantes - por meio da prática educomunicativa, cujo processo de alfabetização se concretizou a partir de um compromisso firmado entre os estudantes e o educomunicador-pesquisador de se reunirem sempre no mesmo dia e horário. Essencialmente, nessa nova sala de aula os estudantes aprenderam a ler e a escrever com um processo tecnológico que propiciou um ambiente favorável à produção de conhecimento, além do compromisso de fazer o que havia sido combinado, gerando um contexto de aprendizado a partir da convivência com os outros colegas. Consequentemente, aprendeu-se que sala de aula é todo lugar onde há o desejo de aprender, ainda mais se há também o prazer de dominar a tecnologia para concretizar o aprendizado.

Mais que aprender a ler e a escrever, a palavra foi vivenciada, experienciada e trouxe à tona alegrias, tristezas e vitórias.

\section{REFERÊNCIAS BIBLIOGRÁFICAS}

ARSEL, Zeynep. Fazendo perguntas com um foco reflexivo: um guia para o planejamento e condução de entrevistas. Revista Interdisciplinar de Marketing, Maringá, v. 8, n. 2, p. 84-98, 2018.

BOAL, Augusto. O teatro do oprimido: e outras poéticas políticas. Rio de Janeiro: Civilização Brasileira, 1991.

FERNANDES, Maria. Os segredos da alfabetização. 2. ed. São Paulo: Cortez, 2010. FREIRE, Paulo. Ação cultural para a liberdade e outros escritos. 6. ed. Rio de Janeiro: Paz e Terra, 1982.

FREIRE, Paulo. Ação cultural para a liberdade. 5. ed. Rio de Janeiro: Paz e Terra, 1981.

FREIRE, Paulo. Extensão ou comunicação? 8. ed. Rio de Janeiro: Paz e Terra, 1985.

FREIRE, Paulo. Pedagogia do oprimido. 17. ed. Rio de Janeiro: Paz e Terra, 1987.

GOLDENBERG, Mirian. A arte de pesquisar. Rio de Janeiro: Record, 1997.

GUILHERME, Manuela. Qual o papel da pedagogia crítica nos estudos de língua e de cultura? Entrevista com Henry A. Giroux. Revista Crítica de Ciências Sociais, [s. l.], n. 73, p. 131-143, 2005.

KOUDELA, Ingrid Dormien; SANTANA, Arão Paranaguá de. Abordagens metodológicas do teatro na educação. Ciências Humanas em Revista, São Luís, v. 3, n. 2, p. 145-154, 2005.

MORAIS, Artur Gomes de; ALBUQUERQUE, Eliana Borges C. Alfabetização e letramento. Recife: Autêntica, 2007. 
comunicação \& educação • Ano XXVI • número 2 • jul/dez 2021

RICHMOND, Mark; ROBINSON, Clinton; SACHS-ISRAEL, Margarete (ed.). O desafio da alfabetização global: um perfil da alfabetização de jovens e adultos na metade da década das Nações Unidas para a alfabetização 20032012. Brasília, DF: Unesco, 2009.

ROOK, Dennis W. Let's pretend: projective methods reconsidered. In: BELK, Russell W. (ed.). Handbook of qualitative research methods in marketing. Cheltenham Glos: Edward Elgar, 2006. p. 143-155.

SOARES, Ismar de Oliveira. Educomunicação: o conceito, o profissional, a aplicação - contribuições para a reforma do ensino médio. São Paulo: Paulinas, 2011.

SOARES, Magda. Letramento e alfabetização: as muitas facetas. Revista Brasileira de Educação, São Paulo, n. 25, p. 5-16, 2004.

STEIN, Suzana A. Por uma educação libertadora. Petrópolis: Vozes, 1985.

THIOLLENT, Michel. Metodologia da pesquisa-ação. 12. ed. São Paulo: Cortez, 2003. 